\title{
Pareto Improvements To Free Trade In An Infinitely Repeated Dynamic Game
}

Gregory G. Green, (E-mail: greegreg@isu.edu), Idaho State University Michael Landrigan, Idaho State University

\begin{abstract}
In an infinitely repeated intraindustry trade game governments improve on the static prisoners dilemma outcome of the Brander and Spencer (1985) trade policy. When firms collude as joint monopolist governments' reach the Pareto frontier of their feasible and individually rational set (FIRS) using a policy of free trade. Free trade and collusion will place firms on the Pareto frontier of their effective feasible and individually rational set (EFIRS). Without collusion free trade forces governments and firms inside their respective FIRS and EFIRS. We demonstrate that without collusion governments return to the Pareto frontier of their FIRS only when taxing exports.
\end{abstract}

\section{INTRODUCTION}

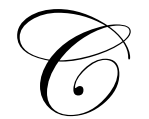

ountries that participated in the General Agreement on Tariffs and Trade (GATT) spent years negotiating multilateral tariff reductions and export subsidy elimination. As GATT evolved into the World Trade Organization (WTO) the agenda items, tariff reduction and export subsidy elimination, did not change. That these policy items have remained so prominent through time is not coincidental, since nearly two-hundred years of economic analysis has shown that in most circumstances free trade will be welfare improving. One exception to the free trade rule are goods that trade in an intraindustry setting, as defined by Brander and Spencer (1985) [henceforth B\&S].

While B\&S were not the first to notice the model intraindustry trade patterns, their model has become the workhorse of the intraindustry trade literature. An important conclusion of B\&S's analysis is that free trade is not an equilibrium outcome. However, as shown by Collie (1993), for example, once the static model of B\&S is cast into the dynamic setting of an infinitely repeated game free trade can be restored to its equilibrium status. We show that active policy, in the form of an export tax, will lead to Pareto improvements relative to free trade. Moreover, we also prove that an export tax is the only policy that leads to a Pareto improvement relative to free trade.

A variation of the $B \& S$ trade model serves as the stage game in our infinitely repeated trade setting. We demonstrate that free trade will increase the value taken by the social benefit function, relative to an infinite repetition of the static B\&S equilibrium, in two separate circumstances. First, when firms are allowed to collude free trade will place governments on the Pareto frontier of the Feasible and Individually Rational Set (FIRS). Second, if firms are not able to collude free trade will still increase the value taken by the social benefit function, even though governments will be inside their FIRS. Consequently, a Pareto improvement is possible. We demonstrate that only an export tax will lead to a Pareto improvement relative to free trade for the governments in the absence of firm collusion. Thus, free trade and an export tax both Pareto dominate an infinite repetition of B\&S's static export subsidy.

Our dynamic setting is similar to the model constructed by Collie (1993). Using this model we demonstrate that free trade is a subgame perfect outcome in the infinitely repeated setting. This result is not new since Collie (1993) also reached this conclusion. However, we extend Collie (1993) by proving that an export tax will generate a Pareto improvement for governments relative to free trade, in the absence of collusion. Collie (1993) alludes to this fact; however, no proof is offered in his writing. 
The present work is similar to Fung (1991), and Lommerud and Sorgard (2001) in only one respect. Like these authors we use a variation of the B\&S's model as a stage game in an infinitely repeated game of intraindustry trade. These authors analyze the impact of collusion, which is viable in an infinitely repeated game, on the firms' trade relation. We analyze a very different problem. We assume that international relations prohibit collusion between firms. This prohibition restricts firms, in our setting, to Cournot behavior. Cournot competition and the absence of collusion will place governments in the interior of their FIRS. Governments move toward the Pareto frontier only if they collude in trade policy. The collusion by governments will generate a Pareto improvement relative to free trade.

The paper proceeds as follows. In section two the model is developed. In section three we present the main results of this paper. In section four we extend the results of section three to a more robust setting. In section four we offer conclusions.

\section{MODEL}

The model is a variation of the B\&S model. There are four players, two governments and two firms, that we model is an extensive form game. Let $N=\{1,2,3,4\}$ represent this set of players, where player 1 is the domestic governments, and player 3 is a domestic firm. Similarly, player 2 is a foreign government, and player 4 is a foreign firm.

In this extensive form game governments move first. Governments will choose a trade policy, either an export subsidy or an export tax. Once trade policy is in place firms compete in output in a common third market, with no sale or consumption of their output in either producing country.

Let

$p\left(x_{3}+x_{4}\right)=a-b\left(x_{3}+x_{4}\right)$

represent the inverse demand for the firms' output in the third country. Throughout this paper a subscript refers to the action choice player i $\in N$; thus, in (1) $x_{i}$ refers to an output choice made by firm $i$. Given (1) define each firm's action space as the compact interval $\mathrm{S}_{i}=[0, \mathrm{a} / \mathrm{b}]$, for

$i=3,4$. With demand defined

$g_{j}=\left(p\left(x_{3}+x_{4}\right)-c+s_{j-2}\right) x_{j}$,

for $\mathrm{j}=3,4$, represents the payoff function of firm $j$. In (2) $\mathrm{s}_{\mathrm{j}-2}$ represents an export subsidy/tax offered to firm $j$ by their respective government. The parameter $\mathrm{c}<\mathrm{a}$ is the constant cost per unit, which is identical for both firms. Thus, the entire expression represents the profit earned by each firm.

Governments will choose an export subsidy, $\mathrm{s}_{i} \geq 0$, or tax, $\mathrm{s}_{i} \leq 0$. Each government will choose a trade policy from the compact interval $\mathrm{S}_{i}=[-(\mathrm{a}-\mathrm{c}) / 2,(\mathrm{a}-\mathrm{c})\}$, for $i=1,2 .{ }^{1}$ Because good $\mathrm{x}$ is consumed in a third country each government's social benefit function,

$g_{i}=g_{i+2}-s_{i} x_{i+2}$,

is the sum of the respective domestic firm's profit and the revenues collected or spent on trade policy.

\footnotetext{
${ }^{1}$ This interval was constructed and justified in Author. A description of how this interval was chosen is also found in Section 4. The compactness of each player's action set is required. This assumption allows us to use existing Folk Theorem to define subgame-perfect equilibria.
} 
The game that has been described is a static extensive form game with a unique solution. The static Nash equilibrium is

$\mathrm{s}^{\mathrm{NE}}=\left(\frac{\gamma}{5}, \frac{\gamma}{5}, \frac{2 \gamma}{5 b}, \frac{2 \gamma}{5 b}\right)$,

where $\gamma=\mathrm{a}-\mathrm{c}$. Using this strategy each player receives

$\mathrm{g}\left(\mathrm{s}^{\mathrm{NE}}\right)=\left(\frac{2 \gamma^{2}}{25 b}, \frac{2 \gamma^{2}}{25 \mathrm{~b}}, \frac{4 \gamma^{2}}{25 \mathrm{~b}}, \frac{4 \gamma^{2}}{25 \mathrm{~b}}\right)$

in payoff.

We now construct an infinitely repeated version of the static model described above. The above model will serve as a stage game for our infinitely repeated game. It should be noted that this stage game has two steps, where we use the term step as defined by Wen (2002).

The average discounted sum

$v_{i}=(1-\delta) \sum_{t=0}^{\infty} \delta^{t} g_{i}(a(t))$

describes each player payoff in the infinitely repeated game. The parameter $0 \leq \delta<1$ represents each players discount factor. The discount factor measures a player's patients, or time cost. Note that the average discounted sum is the same functional form used in the proof of Friedman's (1971) and Fudenberg and Maskin's (1986) Folk theorems. Consequently, the implications of this functional form can be found in Fudenberg and Tirole (1992) for example.

Folk theorems are used to classify the set of subgame perfect equilibria of an infinitely repeated game. The proofs of these theorems are constructive; thus, the proofs describe how to construct the subgame perfect equilibria. Friedman's (1971) theorem is used to construct subgame perfect equilibria that strictly Pareto dominate an infinite repetition of the static Nash equilibrium. Fudenberg and Maskin's (1986) folk theorem demonstrates that for a sufficiently large $\delta$ any payoff in the FIRS is subgame perfect.

Either folk theorem could be used is sections 3 and 4, since we are not concerned with the actual construction of subgame perfect equilibria. We are instead concerned with a set of potential equilibria and the properties of that set. However, the folk theorems of Friedman (1971) and Fudenberg and Maskin (1986) do guarantee that the set that we analyze will be subgame perfect for some value of $\delta$.

The structure of this game can be fully analyzed using the payoff functions $g_{i}$, this is so because the payoffs in the infinitely repeated game are defined as the average discounted sum of the per period payoffs. Let $S=x_{i} \in{ }_{N} S_{i}$ describe all possible strategy combinations in the static game. This set is used to define the FIRS for this set of players. Another interesting set is $X\left(s_{1}, s_{2)}=x_{i} \in\{3,4\} S_{i}\right.$, which describes all possible output combinations as a functions of stage one trade policy. The set $\mathrm{X}\left(\mathrm{s}_{1}, \mathrm{~s}_{2}\right)$ is used when describing the effective feasible and individually rational set (EFIRS) for stage two players. Define the FIRS as

$\mathrm{V}=\left\{\mathrm{v} \mid \mathrm{v}_{\mathrm{i}}(\mathrm{s})>\underline{v}_{\mathrm{i}}\right.$ for all $\left.\mathrm{s} \in \mathrm{S}\right\}$, 
where $\underline{v}_{\mathrm{i}}$ is player $i$ 's minmax value. For the governments this set is easily defined and describes the set of all possible subgame perfect equilibria. For the firms $V$ is a well defined non-empty set. However, once governments have made a policy choice there are many elements of $V$ that are no longer available for firms. Consequently, for the firms we define

$\bar{V}_{f}\left(\mathrm{~s}_{1}, \mathrm{~s}_{2}\right)=\left\{\mathrm{v}_{\mathrm{i}}\left(\mathrm{s}_{1}, \mathrm{~s}_{2}\right) \in \mathrm{V} \mid\right.$ there exists $x_{3}$, and $x_{4}$ such that

$g_{3}\left(\mathrm{~s}_{1}, \mathrm{~s}_{2}, \mathrm{x}_{3}, \mathrm{x}_{4}\right)=\mathrm{v}_{3}$ and $\left.\mathrm{g}_{4}\left(\mathrm{~s}_{1}, \mathrm{~s}_{2}, \mathrm{x}_{3}, \mathrm{x}_{4}\right)=\mathrm{v}_{4}\right\}$,

where $\left(\mathrm{x}_{3}, \mathrm{x}_{4}\right) \in \mathrm{X}\left(\mathrm{s}_{1}, \mathrm{~s}_{1}\right)$, to be the EFIRS. When using Friedman's argument to construct a subgame perfect equilibrium a feasible payoff must come from this set. Otherwise step two players may wish to deviate from agreed upon play. ${ }^{2}$

Below we restrict firms to the passive behavior of always choosing their Cournot equilibrium given trade policy. This assumption will make the choice between Friedman's (1971) or Fudenberg and Maskin's (1986) irrelevant, when we are constructing subgame perfect strategies.

\section{POLICY ANALYSIS}

To simplify the dynamic game assume that firms are not allowed, perhaps by law, to collude, and that this prohibition can be enforced. This will make the firms a passive player in our game, they will take trade policy as given and choose their optimal output as Cournot oligopolists. Given this circumstance governments; will use trade policy to manipulate their social benefit.

For governments define the set of feasible and individually rational payoffs in the usual way. Let

$\mathrm{V}_{\mathrm{g}}=\left\{\mathrm{v} \mid\right.$ there exists some $\mathrm{s} \in \mathrm{S}=\mathrm{S}_{1} \times \mathrm{S}_{2}$ such that $\left.\mathrm{v}=\mathrm{g}(\mathrm{s})\right\}$

represent that set of individually rational payoffs. Then the FIRS is defined by

$\bar{V}_{\mathrm{g}}=\left\{\mathrm{v} \in \mathrm{V}_{\mathrm{g}} \mid \mathrm{v}_{\mathrm{i}}>\underline{v_{i}}\right.$ for all $\left.\mathrm{i}\right\}$,

where $\underline{v_{i}}$ is player $i$ 's minmax value, which is zero for both governments.

Passive firms will always choose their Nash equilibrium output level given trade policy, defined as

$x_{3}=\frac{\gamma+2 s_{1}-s_{2}}{3 b}$

$x_{4}=\frac{\gamma+2 s_{2}-s_{1}}{3 b}$

Substitution of (12) and (13) into (3) defines each government's payoff function as a function of trade policy only.

These functions

$g_{1}^{*}=\frac{\left(\gamma-\mathrm{s}_{1}-\mathrm{s}_{2}\right)\left(\gamma+2 \mathrm{~s}_{1}-\mathrm{s}_{2}\right)}{9 \mathrm{~b}}$

\footnotetext{
${ }^{2}$ It was demonstrated by author that free trade cannot be established as a subgame perfect equilibrium
} 


$$
g_{2}^{*}=\frac{\left(\gamma-\mathrm{s}_{1}-\mathrm{s}_{2}\right)\left(\gamma-2 \mathrm{~s}_{2}-s_{1}\right)}{9 b}
$$

describe each government's stage game payoff, given firms are choosing their Nash equilibrium output levels. Given (14) and (15), and the fact that $S_{i}=[-\gamma / 2, \gamma]$, we find that the

$$
g_{i}^{\mathrm{M}}=\arg \max _{\{s i, s\}} \mathrm{g}_{\mathrm{i}}=\frac{\gamma^{2}}{4 b}
$$

If firms are able they would always deviate from a free trade choice of policy, if the punishment strategy is Friedman's which defines each governments maximum payoff, and

$$
\underline{v}_{i}=\min _{S \mathrm{i}} \max _{s j}=0
$$

for $i=1,2$. These points are defined in Figure 1. The outer bound of the governments FIRS is a linear combination of $g_{1}{ }^{M}$ and $g_{2}{ }^{M}$.

Point B, $\left(2 \gamma^{2} /(25 b), 2 \gamma^{2} /(25 b)\right)$ in Figure 1 represents the payoff each government would receive for an infinite repetition of the static Nash equilibrium. Since point B is on the interior of the FIRS it is immediately obvious that a Pareto improvement could be made for both governments. Any Pareto improvement should be welcomed since the point B payoff represents a prisoners dilemma outcome for governments.

Previous work on the infinite repetition of a B\&S type game focuses on free trade when constructing a subgame perfect equilibrium. Free trade is a natural target, or a natural focal point, and, as mentioned in the introduction, the policy of choice of the World Trade Organization (WTO). Point A, $\left(\gamma^{2} /(9 b), \gamma^{2} /(9 b)\right)$, in Figure 1 represents the free trade payoff combination for the governments. Obviously, free trade increases social benefit relative to an infinite repetition of the static equilibrium, and eliminates the prisoners dilemma outcome. Just as obvious in Figure 1 is that social benefit could increase relative to the payoff combination of point A. Consequently a Pareto improvement is possible. ${ }^{3}$

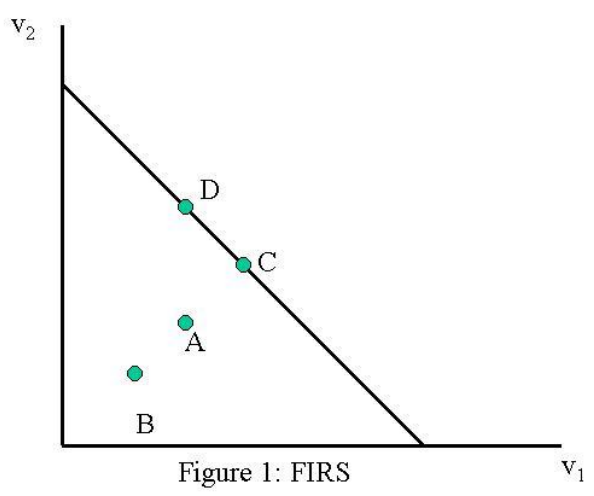

\footnotetext{
${ }^{3}$ This seems an appropriate place to state that governments would be on the Pareto frontier of their FIRS with free trade if firms were allowed to collude. However, if firms are not allowed to collude the governments will never reach their Pareto frontier without the use of trade policy. Thus, social benefit can increase regardless of what is happening to firms.
} 
One possible Pareto improvement would be a strategy that leaves player 1 receiving the free trade payoff, but increases player 2's payoff relative to free trade. One such Pareto improvement is defined at point D in Figure 1. While this point seems arbitrary it will initiate a question regarding policy that we will answer in Proposition 3 . We summarize this particular equilibrium in

Proposition 1 Given the passive behavior of firms the subsidy choice

$\mathrm{s}=\left(-\frac{5}{18} \gamma,-\frac{2}{9} \gamma\right)$

for governments is a Pareto improvement relative to the strategy $s^{f t}=(0,0)$.

Proof. Substitution of $s$ into (14) and (15) results in

$g_{I}(\mathrm{~s})=\frac{\gamma^{2}}{9 b}$

$g_{2}(\mathrm{~s})=\frac{5 \gamma^{2}}{36 b}$

Equation (17) is the free trade equilibrium payoff. The boundary of the FIRS is defined by

$v_{2}=-v_{1}+\frac{\gamma^{2}}{4 b}$

Substitution of $v_{1}=g_{1}$ (s) into (19) defines $v_{2}=g_{2}(\mathrm{~s})$, which is greater than the free trade payoff. Together (17) and (18) define point D in Figure 1. No player is worse off given these payoffs and the foreign government is strictly better off using this strategy. Consequently (17) and (18) define a Pareto improvement.

The policy choice used in Proposition 1 defines a Pareto improvement relative to free trade. At the same time it identifies two interesting points. First, while this outcome is a Pareto improvement, relative to free trade, it is not equitable. The domestic government may be disturbed at the fact that the foreign government is receiving a strictly greater payoff than is the domestic government. The second observation is perhaps more interesting. For this Pareto improvement governments must both use an export tax.

Equity seems to be an issue in trade policy. This is evident in arguments request that firms have an equal playing field in trade. The issue of equity is easily analyzed using the present form of our trade model. To define an equitable Pareto improvement we require that

$\mathrm{s}_{1}=\mathrm{s}_{2}$, which will result in $v_{1}=v_{2}$.

Proposition 2 Suppose that firms are passive and that $s^{\prime}=s_{1}=s_{2}$. Any strategy $s^{1} \in[-\gamma / 2,0]$ will lead to a Pareto improvement for the governments relative to the free trade outcome. 
Proof. The proof amounts to finding a solution in $s^{\prime}$ to

$\left(s^{\prime}+\gamma\right)\left(\gamma-2 s^{\prime}\right)-\gamma^{2} \geq 0$,

which reduced to

$-s^{\prime}\left(2 s^{\prime}+\gamma\right) \geq 0$.

The solution to (21) is $s^{\prime} \in[-\gamma / 2,0]$, which completes the proof.

Using the strategy $s^{\prime}=-\gamma / 4$ each government's social benefit would reach $v_{i}=\gamma^{2} /(8 b)$. This payoff is on the Pareto frontier, point $\mathrm{C}$ in Figure 1, and is the same payoff that governments would receive with free trade and firms producing and splitting the joint monopoly output level and profits.

Why should an export tax be preferred to free trade with collusion? Obviously foreign consumers are paying the same price in either case. So it is not a question of income distribution in the export market. It is, however, an issue of income distribution in each of the producing countries. With an export tax income is being redistributed from each producer to their respective government. Thus, the export market provides a source of revenue to each government. With free trade and collusion governments lose this source of revenue, which is transferred to the producers.

Proposition 2 defines all of the equitable Pareto improvement, relative to free trade, for the governments. Any $s^{\prime} \in[-\gamma / 2,0]$ generates a payoff along the line connecting points $\mathrm{B}$ and $\mathrm{C}$ in Figure 1 . Furthermore, the symmetric strategy of Proposition 2 suggests that the tax used to reach the Pareto frontier is roughly the same magnitude, $1 / 4 \gamma$ instead of $1 / 5 \gamma$, as the subsidy used in the static equilibrium.

As in Proposition 1 Proposition 2 states that any equitable Pareto improvement requires an export tax. In general suppose that firms are not allowed to collude. What policy combinations would create a Pareto improvement, relative to free trade, for the governments? The answer to this question lies in the simultaneous solution of

$$
\frac{\left(\gamma-s_{1}-s_{2}\right)\left(\gamma-s_{2}+2 s_{1}\right)}{9 \mathrm{~b}}-\frac{\gamma^{2}}{9 \mathrm{~b}} \geq 0
$$

And

$$
\frac{\left(\gamma-s_{1}-s_{2}\right)\left(\gamma-s_{1}+2 s_{2}\right)}{9 \mathrm{~b}}-\frac{\gamma^{2}}{9 \mathrm{~b}} \geq 0
$$

Proposition 3 The only simultaneous solutions to (22) and (23) are for $s_{1}$ and $s_{2}$ which are both non-positive.

Proof. First consider only (22); actually we ignore the $9 \mathrm{~b}$ 's in the denominators since they have no affect on the solution set. Multiplying out the left side, setting it equal to zero and solving for $s_{2}$ we get

$s_{2}=\frac{2 \gamma+s_{1} \pm \sqrt{4 \gamma^{2}+9 s_{1}^{2}}}{2}$

So there are two components to the solution set, one at and above the "plus" curve and one at and below the "minus" curve, as in Figure 2. 


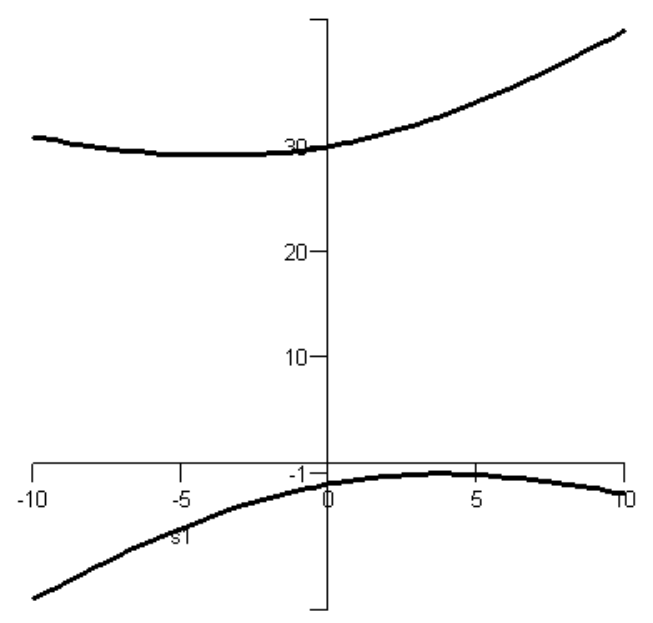

Figure 2: Curves with $\gamma=14$

Claim 1: All of the solutions in the upper component have $s_{2}>\gamma$, so we exclude these, recall that $S_{i}=[-\gamma / 2, \gamma]$, for governments.

For a solution in the upper component we have

$s_{2} \geq \frac{2 \gamma+s_{1}+\sqrt{4 \gamma^{2}+9 s_{1}^{2}}}{2} \geq \frac{2 \gamma+s_{1}+2 \gamma}{2}>2 \gamma$

Claim 2: All of the solutions in the lower component are below the line $s_{2}=\mathrm{s}_{1} / 2$.

To see this we just check that

$s_{2} \leq \frac{2 \gamma+s_{1}-\sqrt{4 \gamma^{2}+9 s_{1}^{2}}}{2}<\frac{2 \gamma+s_{1}-2 \gamma}{2}=\frac{s_{1}}{2}$.

We use this second claim to finish. We first note that the solution set to (23) is exactly the solution set to (22) reflected over the line $s_{1}=s_{2}$, i.e. (a, b) is a solution to (23) if and only if (b, a) is a solution to (22). From this it follows that the only solutions to (23) are above the line $s_{2}=2 s_{1}$, and so the only possible simultaneous solutions are in the third quadrant with $s_{1}$ and $s_{2}$ both non-positive. 


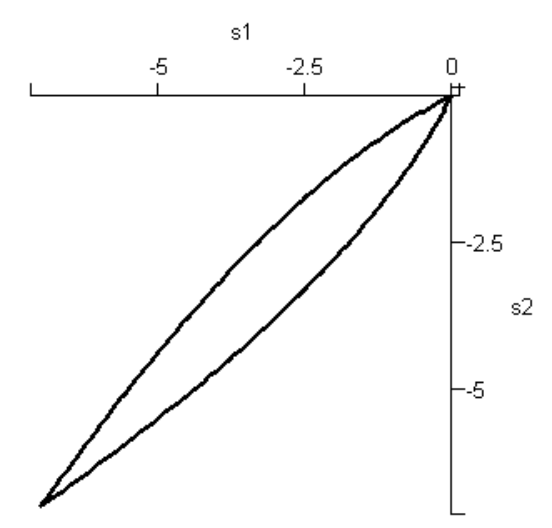

Figure 3: Solution set to (22) and (23) with $\gamma=14$.

Proposition 3 demonstrates that a Pareto improvement for governments, relative to free trade, requires an export tax.

Switching from a static to a dynamic model of intraindustry trade moved governments out of the prisoners dilemma found in the static game. Elimination of the prisoners dilemma only requires that governments use free trade policy. However, when firms are unable to collude, we have shown that collusion between governments will increase their payoff even more, relative to free trade.

Propositions 2 and 3 demonstrate how a dynamic game shifts the focus of trade policy away from producers, the static case, and places the focus of policy directly on the governments. In the static case foreign consumers and domestic producers gain at the expense of domestic consumers and the domestic government. With free trade and firm's colluding domestic producers gain at the expense of foreign consumers, that are now paying the monopoly price. With an export tax, and firms unable to collude, and if governments can collude each government will gain at the expense of foreign consumers and their respective domestic producer.

Tacit collusion by firms is certainly feasible, especially with price competition. However, not allowing firms to collude is a reasonable supposition, especially with quantity competition. Furthermore, in the United States and the rest of the industrialized world anti trust laws are used to prohibit explicit collusion by firms. Without the ability to collude governments will receive a payoff inside of their FIRS. To move toward the Pareto frontier of the governments FIRS active trade policy, in the form of an export tax, would definitely be feasible.

\section{ASYMMETRIC COSTS}

An interesting extension of Proposition 3 would be to analyze a similar trade game in which costs are asymmetric. Costs may differ based on differences in technology in production. However, given the industry structure large cost differentials may not be expected on technology grounds. A very reasonable explanation for cost differences in our trade game would be geographic distance to market.

Suppose that the domestic firm has a constant cost per unit of $c_{3}$ and the foreign firm has a constant cost per unit of $c_{4}$. Suppose that $c_{3} \neq c_{4}$. We maintain the assumption that firms cannot collude, they simply choose a Cournot output level given trade policy. Given these assumptions

$g_{1}\left(s_{1}, s_{2}\right)=\frac{\left(a-s_{2}-2 c_{3}+2 s_{1}+c_{4}\right)\left(a-2 c_{3}+c_{4}-s_{1}-s_{2}\right)}{9 b}$ 


$$
g_{2}\left(s_{1}, \mathrm{~s}_{2}\right)=\frac{\left(\mathrm{a}-\mathrm{s}_{1}-2 \mathrm{c}_{4}+2 \mathrm{~s}_{2}+\mathrm{c}_{3}\right)\left(\mathrm{a}-2 \mathrm{c}_{4}+\mathrm{c}_{3}-\mathrm{s}_{1}-\mathrm{s}_{2}\right)}{9 \mathrm{~b}}
$$

represents the payoff functions of the two governments.

With asymmetric costs we must reanalyze the bounds on $S_{1}$ and $S_{2}$. These bounds are derived from analysis of the firms' reaction functions. We define $S_{1}=\left[-\left(-a-2 c_{3}+c_{4}\right) / 2, a-2 c_{4}+c_{3}\right]$. If the foreign government were to choose free trade and the domestic government chose the lower bound of $S_{I}$ the domestic firm would be completely pushed out of the export market. Similarly, if the foreign government were to choose free trade and the domestic government were to choose the upper bound of $S_{1}$ the foreign firm would be pushed completely out of the export market. Similarly, $S_{2}=\left[-\left(a-2 c_{4}+c_{3}\right) / 2, a-2 c_{3}+c_{4}\right]$ represents a foreign governments strategy set.

Choosing $S_{1}$ and $S_{2}$ in this manner may seem arbitrary. A more natural choice might be for consumers to place a bound on how much they are willing to pay out in subsidies. If firms had a capacity constraint on output a cap may naturally occur as well. While these natural constraints probably exist we maintain that our choice of boundary remains rich enough to give very reasonable outcomes.

If costs are different across firms, the outer boundary of the FIRS will shift, relative to previous analysis. However, the outer bound is still a linear combination of the maximum payoff of each government. The maximum occurs when the government's domestic firm produces as a monopolist. This maximum will be lower for the high cost firm.

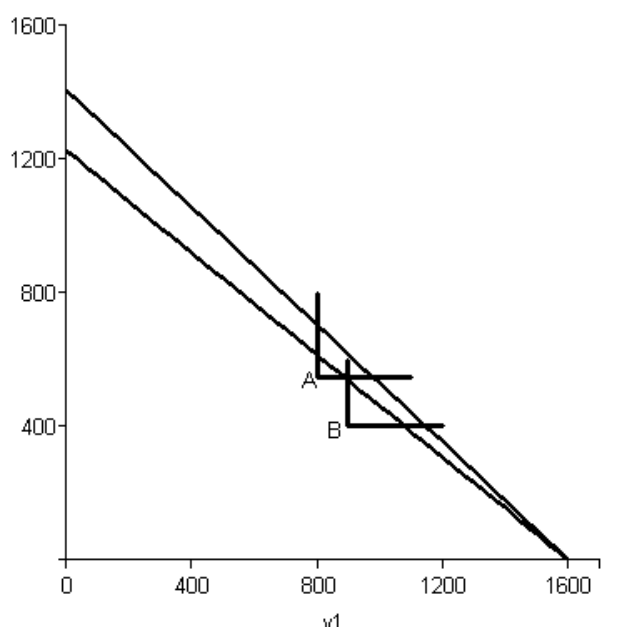

Figure 4: FIRS with cost difference across firms

Even with the change in FIRS free trade will still be within the set of feasible and individually rational payoffs, see Figure 4. Figure 4 represents the FIRS for two different cost combinations. In both cases we assume that $c_{4}>c_{3}$. Point A represents one free trade combination. The two rays extending outward from point $\mathrm{A}$ are to illustrate that a Pareto improvement is possible, relative to free trade. If $c_{4}$ were to rise while $c_{3}$ remained constant the free trade position would move to point B. At point B player 1s payoff would increase relative to player $2 \mathrm{~s}$; however, a Pareto improvement is still possible relative to point B. However, the free trade payoff

$g^{1}(0,0)=\frac{\left(a-2 c_{3}+c_{4}\right)^{2}}{9 b}$ 


$$
g^{2}(0,0)=\frac{\left(a-2 c_{4}+c_{3}\right)^{2}}{9 b}
$$

will no longer be symmetric, except in the special case of $c_{3}=c_{4}$. The low cost firm will produce more output and generate more profits, which will translate into a higher social benefit for the country with the low cost firm.

With asymmetric costs it is difficult to say what an equitable Pareto improvement would be. However, both governments could still reach a Pareto improvement relative to the free trade payoff. Finding this Pareto improvement amounts to finding a simultaneous solution to the inequalities

$$
\left(a+c_{4}-2 c_{3}-s_{1}-s_{2}\right)\left(a+c_{4}-2 c_{3}+2 s_{1}-s_{2}\right)-\left(a+c_{4}-2 c_{3}\right)^{2} \geq 0
$$

and

$$
\left(a+c_{3}-2 c_{4}-s_{1}-s_{2}\right)\left(a+c_{3}-2 c_{4}-s_{1}+2 s_{2}\right)-\left(a+c_{3}-2 c_{4}\right)^{2} \geq 0
$$

for values $s_{1}$ and $s_{2}$ which satisfy

$$
-\left(a+c_{4}-2 c_{3}\right) / 2 \leq s_{1} \leq a+c_{3}-2 c_{4} \text { and }-\left(a+c_{3}-2 c_{4}\right) / 2 \leq s_{2} \leq a+c_{4}-2 c_{3} .
$$

To simplify the algebra in the following we set $u=a+c_{4}-2 c_{3}$ and $v=a+c_{3}-2 c_{4}$. Rewriting the inequalities, we are interested in solutions to four inequalities.

$$
\begin{aligned}
& \left(u-x_{1}-s_{2}\right)\left(u+2 s_{1}-s_{2}\right)-u^{2} \geq 0 \\
& \left(v-s_{1}-s_{2}\right)\left(v+2 s_{2}-s_{1}\right)-v^{2} \geq 0 \\
& -u / 2 \leq s_{1} \leq v \\
& -v / 2 \leq s_{2} \leq u
\end{aligned}
$$

Proposition 4 The only solutions to equations (31) through (34) are for $s_{1}$ and $s_{2}$ which are both non-positive.

Proof. First we obtain a general description of the solution set for (31); a similar description holds for (32).

Multiplying out the left side of (31), setting it equal to zero and solving for $s_{2}$ we get

$s_{2}=\frac{2 u+s_{1} \pm \sqrt{4 u^{2}+9 s_{1}^{2}}}{2}$.

So there are two components to the solution set, one at and above the "plus" curve and one at and below the "minus" curve.

Claim: There are solutions to the inequalities only if $u$ and $v$ are both positive. (This is reminiscent to the $a-c>0$ condition of section 3.) 
If $u$ and $v$ are both negative, then there are patently no solutions to (33) and (34). If $u>0$ and $v<0$, then the following considerations show that (31) has no solution. (Similarly if $u<0$ and $v>0$, then (32) has no solutions.)

For a solution in the upper component of (31) we would have

$s_{2} \geq \frac{2 u+s_{1}+\sqrt{4 u^{2}+9 s_{1}^{2}}}{2} \geq \frac{2 u+s_{1}+2 u}{2} \geq \frac{2 u-u / 2+2 u}{2}=\frac{7}{4} u$.

So there are no solutions there. For solutions in the lower component we would have

$s_{2} \leq \frac{2 u+s_{1}-\sqrt{4 u^{2}+9 s_{1}^{2}}}{2} \leq \frac{2 u+s_{1}-2 u}{2}=s_{1} / 2$.

But in this situation (33) and (34) imply that $s_{1}<0$ and $s_{2}>0$, a contradiction. So the lower component also has no solutions. This establishes the claim.

Now to prove that the only solutions are for $s_{1} \leq 0$ and $s_{2} \leq 0$ we argue in a similar way, assuming that both $u$ and $v$ are positive.

Inequality (35) still shows that the upper component of (31) has no solutions. Similarly the right component of (32) has no solutions. So we need to only consider the lower (right) components of (31) and (32). For this inequality (36) shows that the solutions to (31) must satisfy $s_{2} \leq s_{1} / 2$. The similar inequality for (32) shows that $s_{1} \leq s_{2} / 2$. The only simultaneous solutions to these are for $s_{1} \leq 0$ and $s_{2} \leq 0$.

The results of Proposition 4 state that even with differences in geographical location to market an export tax will lead to Pareto improvement in social benefit in a dynamic setting. Thus, given our model we can conclude that an export tax will under all circumstances provide a Pareto improvement relative to free trade. Furthermore, since the payoffs are within the governments FIRS there must exist some $\delta$ such that these Pareto improving payoffs would be subgame perfect.

\section{CONCLUSION}

In a dynamic setting there are infinitely many potential subgame perfect outcomes. In the infinitely repeated intraindustry trade policy game free trade is a logical focal point. However, we have shown that active policy, in the form of an export tax, will lead to a Pareto improving payoff, relative to free trade, for both governments. This result is fairly robust with respect to changes in cost. It was shown that even when per unit costs are not equal across firms export taxes will still lead to Pareto improvements relative to free trade.

When choosing trade policy a dynamic setting may be preferred to a static setting. An obvious reason for a dynamic setting to be preferred is the trade relation itself. Like the dynamic model current trade relations are enforced through a punishment phase. Punishment is used to deter deviation from negotiated and established policy. Dynamic policy will also eliminate the prisoners' dilemma outcome of the static game. This characteristic of a dynamic model gives the governments more control over their own payoff.

Allowing trade to occur between the two producing countries, which would make consumption occur in the producing countries, would be an interesting extension of the present research. By including consumers in the model a natural boundary on the size of a government's policy instrument may appear. It seems reasonable that this boundary be chosen endogenously. 
An interesting question is what kind of discount factor is needed to establish an export tax as a subgame perfect equilibrium? We have shown that governments can improve upon free trade payoffs using export taxes. However, are these governments patient enough to make an export tax a feasible policy?

\section{REFERENCES}

1. Brander, J., Spencer, B., Export Subsidies and International Market Share Rivalry, Journal of International Economics 18 (1985): 83-100.

2. Collie. D., Profit-Shifting Export Subsidies and the Sustainability of Free Trade, Scottish Journal of Political Economy 40 (1993): 408-419.

3. Friedman, J., A Non-Cooperative Equilibrium for Supergames, Review of Economic Studies 38 (1971): $1-12$.

4. Fudenberg D., Maskin E., The Folk Theorem in Repeated Games With Discounting or with Incomplete Information, Econometrica 54 (1986): 533-554.

5. $\quad$ Fudenberg, D., Tirole, J., Game Theory, Bosten: MIT press (1992).

6. Fung, K.C., Collusive Intraindustry Trade, Canadian Journal of Economics 24 (1991): 391-404.

7. Lommerud, K.E., Sorgard, L., Trade Liberalization and Cartel Stability, Review of International Economics 9 (2001): 343-355.

8. Wen, Q., A Folk Theorem for Repeated Sequential Games, Review of Economic Studies 69 (2002): 493512.

\section{NOTES}


NOTES 